\title{
Relaciones entre la sociología y la antropología jurídica en Latinoamérica*
}

\section{Relationships between the Legal Sociology and Anthropology in Latin America}

Fecha de recepción: 20 de octubre de 2010

Fecha de aprobación: 18 de noviembre de 2010

\author{
Jairo Vladimir Llano**
}

\section{Resumen}

La sociología y la antropología jurídica en el transcurso del siglo XX han tenido un reconocimiento por la ciencia jurídica anglosajona y continental europea a través de debates como el correspondiente al pluralismo jurídico que involucra a ambas especialidades. Por su parte, en Latinoamérica tiene su aparición de forma disciplinaria sólo a mediados de la década de los noventa del siglo pasado, trasladando el debate teórico-práctico del pluralismo jurídico con las connotaciones particulares que caracterizan la región por su diversidad cultural y jurídica.

Palabras clave: ciencia jurídica, sociología jurídica, antropología jurídica, pluralismo jurídico, conflicto, Latinoamérica.

* Artículo de investigación que fue presentado en su fase inicial en los 20 años del Instituto Internacional de Sociología Jurídica de Oñati (España) que se conmemoró en julio de 2009.

** Antropólogo y especialista en antropología jurídica de la Universidad del Cauca, actualmente se encuentra terminando los estudios de doctorado en Derecho en la Universidad Externado de Colombia, realizó estancia de investigación en el Instituto Internacional de Sociología Jurídica de Oñati, profesor de la Facultad de Derecho de la Universidad Santiago de Cali en filosofía del derecho y sociología jurídica, hace parte del centro de investigaciones de dicha Universidad y dirige el grupo de investigación "Eduardo Umaña" en categoría B por Colciencias. Correo electrónico: vmonsalve@uninorte.edu.co 


\begin{abstract}
Legal sociology and anthropology in the course of the $20^{\text {th }}$ century have been recognized for by the Anglo-Saxon and continental European legal science throught debates like the one corresponding to legal pluralism which involves both specialties. For its part in Latin America the appearance of this disciplinary form takes place only around the middle of the nineties, moving theoretical-practical debate of the legal pluralism with the particular connotations that characterize the region for its cultural and legal diversity
\end{abstract}

Key words: laws of science, sociology of law, anthropology of law, legal pluralism, conflict, Latin America.

\section{PRESENTACIÓN}

Hasta los inicios de los años noventa la sociología y la antropología jurídica eran especialidades de la ciencia jurídica consideradas marginales para el contexto académico latinoamericano, distinto a lo que sucedía en el contexto anglosajón y continental europeo donde tenían una tradición de décadas que retroalimentaban el saber jurídico en los espacios de formación por medio de investigaciones y debates teóricos que perduran hasta los tiempos recientes; entre las reflexiones a que acudieron estas especialidades y que se puede considerar un punto de encuentro esta el pluralismo jurídico como propuesta que comprende los conflictos y las prácticas jurídicas que los resuelven en lo local, lo regional y lo global, en contradicción de la perspectiva del positivismo jurídico que reconocía sólo el derecho estatal y que perduró por varias décadas. Estas concepciones interdisciplinarias del pluralismo jurídico que se realizaban en los contextos de centrales y de reconocimiento académico e investigativo fueron trasladados paulatinamente a la academia latinoamericana hasta mediados de los años noventa en pleno proceso de transformaciones y reformas constitucionales.

Precisamente, los estudios en que coinciden la sociología y antropología jurídica en los contextos anglosajón y continental, el pluralismo jurídico también se trasladó de forma renovada al contexto académico latinoamericano cuyos debates y publicaciones tienen su amplia referencia a me- diados de la década del noventa; situación que se presentaba por desconocimiento, en el caso de los programas de derecho, se enseñaba como fuente única y esencial productora de derecho al Estado nacional, por medio del legislador soberano, el parlamento, práctica que es denominada como monismo. La concepción monista del derecho ha dominado la cultura jurídica al menos durante tres siglos, a partir de la consolidación del Estado moderno, en particular el Estado nacional, como entidad política soberana tanto en el ámbito interno como en el externo. Soberanía interna significa monopolio del poder, del uso de la fuerza y en general, de los instrumentos coactivos: por tanto, de la producción y de la aplicación del derecho, entendido como única norma para la regulación de las relaciones sociales $y$, por eso mismo, para la legitimación del uso de la fuerza (Ferrari, 2000, p. 53).

\section{DEL DERECHO ESTATAL AL PLURALISMO JURÍDICO}

Desde los inicios del siglo XX la concepción monista se encontraba cuestionada por teóricos del derecho continental europeo como lo referencia Bobbio desde la teoría institucional, la doctrina de la institución representa una reacción contra el estatalismo y es uno de los tantos medios con lo cual los teóricos del derecho y de la política han tratado de oponerse a la expansión del estatalismo. La doctrina nace de las revaluaciones de las teorías jurídicas de la tradición cristiana, 
como en el caso de Georges Renard (ver la Théorie de l'insititution, 1930), ya de la influencia de las corrientes socialistas libertarias (Proughon), o anárquicas, o sindicalistas como el caso de Georges Gurvitch (ver L'idée du droti social y la Dichia razione dei diritti sociali, 1949) y se convierte en teoría del derecho en Francia con Murice Haurio, y en Italia con Santi Romano [...]. Encontró fecunda aplicación en el estudio de ordenamientos particulares o de situaciones concretas por parte de un filósofo del derecho, Cesarini-Sforza, quien estudia el derecho de los particulares, es decir, el ámbito de la llamada "autonomía privada" como un ordenamiento jurídico diferente del ordenamiento estatal (Bobbio, 1999, p. 10).

Entre otros teóricos que consideraban la práctica social como fuente de derecho y los posteriores adelantos de neo-positivistas como Kelsen desde la relación del derecho estatal con el derecho internacional, alejándose Kelsen de la teoría estatalista tradicional -que podemos comprobar por el hecho de que él califique la teoría tradicional como "dualista", y no ya como "monista", por estar basada en la contraposición entre ordenamiento estatal y ordenamiento internacional- se hace más evidente aún en el momento en que el autor extiende su propia concepción monista hasta rechazar por ideológico y subjetivo, "el dogma de la soberanía del Estado", y hasta reducir ad unum, tanto por razones de lógica conceptual como de evolución histórica política, toda la construcción universal del derecho: de manera que el Estado pasa a configurarse como un mero "órgano de la comunidad jurídica internacional" identificada a su vez con un único ordenamiento jurídico general (Ferrari, 2000, pp. 254-255).

Estas concepciones que cuestionan al derecho estatal y que reflexionan sobre la relación del derecho con la realidad social tienen en la especialidad de la sociología jurídica el respaldo disciplinario, esta especialidad en el contexto latinoamericano ha tenido particulares avances, es así como los programas de sociología que se imparten en las universidades latinoamericanas han desarrollado tímidamente la especialidad de la sociología jurídica, situación que contradice la producción de autores europeos de renombre en esta especialidad como Max Weber quien consideraba al derecho como esencial para el funcionamiento del Estado moderno capitalista, el "progreso" hacia lo burocrático, hacia el Estado que juzga y administra, así mismo, conforme a un derecho estatuido y a reglamentos concebidos racionalmente, está en la conexión más íntima con el desarrollo capitalista moderno. La empresa capitalista moderna descansa internamente ante todo en el cálculo. Necesita para su existencia una justicia y una administración cuyo funcionamiento pueda calcularse racionalmente, por lo menos en principio, por normas fijas generales con tanta exactitud como puede calcularse el rendimiento probable de una maquina (Carduño \& Silva, 1998, p. 433).

Otro de los autores influyentes desde la sociología ha sido Marx, precisamente, la sociología jurídica crítica europea y norteamericana tiene entre sus referencias teóricas fundamentales la propuesta marxista: en Marx la cuestión de la "crítica" asume un significado muy particular y distinto. Al examinar la economía política de su época, Marx se rebeló contra el modo en que los economistas clásicos describieron las leyes del capital. Ellos presentaban formulaciones supuestamente científicas que no reflejaban la realidad de los hechos ni de las relaciones sociales. Sus contribuciones no eran erradas, sino planteadas de manera engañosa, y esto llevaba a escamotear y ocultar las verdaderas prácticas sociales. Así la "crítica" aparece en el marxismo como el discurso revelador y desmitificador de las ideologías ocultas que proyectan los fenómenos de forma distorsionada (Wolkmer, 2003, p. 21). El poco avance de la sociología jurídica desde la misma disciplina sociológica en el contexto latinoamericano lleva al desconocimiento del pluralismo jurídico como concepto y teoría, sólo a partir de mediados de 
Ios noventa aparecerán las primeras publicaciones que de forma sorprendente serán dirigidas por abogados especializados en sociología jurídica.

Las investigaciones holísticas como paradigma que ha caracterizado la antropología cultural por varias décadas se transformó en la segunda mitad del siglo XX por la imposibilidad de describir y analizar al mismo tiempo, y por un solo antropólogo aspectos lingüísticos, políticos, médicos, económicos, históricos, arqueológicos, jurídicos, ecológicos, entre otros; situación metodológica que llevaría a la consolidación de las especialidades como la antropología jurídica, que tiene cierto reconocimiento académico a partir de las reformas y transformaciones constitucionales en la década del noventa en las naciones latinoamericanas, introduciéndose paulatinamente en el debate del pluralismo jurídico con estudios y publicaciones a finales del siglo XX e inicios del XXI.

El pluralismo jurídico como concepto científico tiene sus inicios en Europa con más de un siglo, surgió durante el cambio del siglo pasado al presente en la filosofía jurídica anti positivista, como reacción contra la reducción del derecho al derecho estatal, hecha por el movimiento codificador y desarrollado por el positivismo jurídico. Fue una reacción contra el centralismo o del exclusivismo estatal, fundada en un argumento según el cual el derecho estatal estaba en realidad lejos de ser exclusivo y en algunos casos incluso no era central en la ordenación normativa de la vida social (Boaventura, 1998, p. 24). Sin embargo el concepto es referenciado en el contexto de la academia latinoamericana, particularmente en los programas de derecho y antropología de forma reciente, y son varios los profesores e incluso algunos investigadores de la ciencia jurídica que siguen asombrándose con el término y las implicaciones que tienen en el ámbito de la teoría del derecho, la sociología y la antropología jurídica contemporánea.
La disciplina del derecho es concebida como parte de las ciencias sociales, no obstante, su relación con las otras disciplinas del campo social en la formación universitaria es precaria y marginal en la mayoría de los programas académicos, interesándose de forma exclusiva las universidades de mayor prestigio académico, que incentivan las cátedras y las investigaciones en filosofía, historia, sociología y antropología del derecho, conformando equipos interdisciplinarios que se adecuan fácilmente a las propuestas innovadoras de la ciencia jurídica en el contexto internacional, como por ejemplo el fenómeno de globalización del derecho, mientras en los programas de derecho de menor prestigio académico y profesional prevalece la enseñanza de la técnica jurídica, contradiciendo de antemano el papel universitario y sus prácticas que deben de diferenciarse de otros espacios formativos considerados como técnicos y tecnológicos.

Los avances interdisciplinarios en la ciencia social y la jurídica en Latinoamérica son considerados innovadores pese a los esfuerzos que se deben reconocer de las universidades más consolidadas académicamente como la UNAM de México, USP y Santa Catarina de Brasil, la UCBA y la Universidad de Córdoba de Argentina, Nacional y Externado de Colombia. Las tradiciones y las identidades de lo disciplinario impiden se dialogue de forma flexible entre los estudiantes y profesionales de una y otra disciplina sobre ciertos problemas comunes, por ejemplo: los sociólogos se limitan tanto en su formación como en su práctica profesional a realizar investigaciones de las sociedades contemporáneas por medio de la estadística social; los antropólogos se dirigen hacia los estudios de las culturas del pasado por medio de las técnicas arqueológicas o los colectivos indígenas, campesinos o negros alejados de lo citadino a través del método etnográfico; los abogados consideran la aplicación y la interpretación de la ley por medio 
de la hermenéutica tradicional que produce y crea el legislador como derecho; situaciones que contradicen las fuentes teóricas y metodológicas recientes que traspasan la tradición disciplinaria.

\section{PLURALISMO JURÍDICO DESDE LAS ESPECIALIDADES JURÍDICAS}

La primera publicación teórica y conceptual desde la sociología y la antropología jurídica que tiene desarrollos teóricos y conceptuales sobre el pluralismo jurídico se origina en un espacio de reflexión académica distinta al universitario, como es el Instituto de Servicios Legales Alternativos (ILSA) con publicaciones sobre pluralismo jurídico o temáticas relacionadas por profesores e investigadores provenientes de distintos países latinoamericanos, planteando de forma irreverente y novedosa para la mayoría de los abogados, profesores y expertos del derecho, una concepción alejada rotundamente del positivismo y que tenía su soporte en otras formas de producción jurídica que escapaban al monopolio del derecho estatal. Entre los investigadores de ILSA que reflexionan sobre el pluralismo jurídico se encuentra Héctor León Moncayo con una concepción del derecho más allá de lo estatal, una primera constatación nos muestra que el derecho no se reduce a la producción y monopolio estatal y que formas jurídicas pueden encontrarse en ámbitos no "oficiales", particularmente en los medios populares urbanos llamados marginales, tocando así la problemática que desde otros ángulos ha sido denominada pluralismo jurídico. Dicha constatación, analizada bajo la nueva metodología, sugiere inmediatamente una analogía con la transición entre las formas precapitalistas y capitalistas del derecho, conduciendo así a interrogantes fundamentales pues las primeras habitualmente se consideran también como prejurídicas. Es decir, se negaría a definir el derecho exclusivamente como aquello que deviene de la individualización, la constitución del sujeto, el contrato, la abstracción, y la diferen- ciación progresiva de un Estado, separado de la sociedad civil (Moncayo, 1991, p. 8).

Los estudios sobre el pluralismo jurídico se origina en la academia jurídica latinoamericana y colombiana en particular por la entrada de profesores investigadores de otros contextos especialistas en la sociología jurídica que para el momento histórico como cátedra o curso en el pregrado era desconocida excepto en ciertos programas de prestigio y donde contradictoriamente se formaban $y$ forman las elites que ya preparaban a sus futuros profesores en universidades extranjeras, y que en sus visitas periódicas a las universidades patrocinadoras de sus estudios comenzaban tímidamente a plantear la posibilidad de lo sociojurídico como complemento esencial para la formación del abogado. En torno a la propuestas de ofertar especializaciones en el espacio de la sociología, la antropología y la filosofía del derecho la pretensión era aún más remota, entre la que se puede determinar cómo entre las primeras publicaciones sobre el pluralismo jurídico contemporáneo se encuentra: Estado, derecho y luchas sociales, del profesor e investigador portugués Boaventura Santos, quien introduce la mirada renovada en términos de la academia latinoamericana sobre el pluralismo jurídico de acuerdo con las realidades brasileras donde realiza sus primeros trabajos de campo.

Precisamente, Boaventura inicia su reflexión académica con el debate marginal que han tenido el reconocimiento de otras formas de derecho distintas al estatal por parte de la especialidad de la ciencia jurídica en la que se formó el autor, la sociología del derecho; Boaventura comienza su exposición con criticas tanto a la sociología del derecho positivista como a la sociología marxista por su no compresión de la existencia de otros derechos distintos al estatal: La verdad, no sólo la cuestión de la producción jurídica no estatal (fuera del Estado, paralela al Estado o incluso contra el Estado) es aún hoy uno de los tabúes de la teoría 
sociológica del derecho, tanto dentro como fuera del marxismo, como también el discurso y de la argumentación jurídica continúan siendo uno de los temas en que más absoluto el divorcio entre la sociología y la antropología del derecho, por un lado, y la filosofía del derecho, por otro. En lo que respecta al discurso, en especial al discurso jurídico, la sociología positivista del derecho lo considera poco controlable por los métodos de la razón técnica que constituyen la base de su cientificidad, en cuanto que la sociología marxista tiende a ver en él a un objeto teórico de extracción idealista no comprensible en sus propios términos y apenas si aplicable a la luz de la crítica de la ideología. Para ambos paradigmas sociológicos, el discurso jurídico es un área al margen del estudio de las estructuras de poder y del control social en la sociedad contemporánea y como tal puede ser dejado al dominio de la especulación filosófica (Boaventura, 1991, p. 24).

Este análisis desde la sociología jurídica para el contexto latinoamericano es incluso más difícil debido a la fragilidad en unos casos y ausencia en otros de estas especialidades pese a los avances que se han tejido en el contexto anglosajón desde los inicios del siglo XX: El auge de la sociología del derecho en Estados Unidos está relacionada con la llamada tradición crítica del derecho iniciada por el realismo jurídico durante la década de 1920. Los realistas se enfrentaron a la cultura jurídica liberal dominante en la academia legal estadounidense de finales del siglo XIX y denunciaron el carácter marginal, indeterminado y político de la práctica jurídica contra las pretensiones de neutralidad y determinación por el pensamiento dogmático jurídico. Para tal efecto, utilizaron, por un lado, el razonamiento lógico para poner en evidencia la falta de coherencia de las decisiones judiciales, lo cual fue denominado en aquel entonces como "desmonte". Por otro lado, los realistas abogaron por el uso de las ciencias sociales y en particular por la investigación empírica como instrumentos para la explicación objetiva de los procesos jurídicos, de tal manera que se pusiera en evidencia la manera como el derecho logra o no determinar las conductas sociales (García, 2003, p. 3.).

También se reconocen los aportes europeos desde décadas atrás, ha sido la jurisprudencia misma quien ha contrapuesto, a partir del final del siglo pasado, una corriente de pensamiento "antiformalista" que, señalando el carácter equívoco de aquellas proposiciones y la consiguiente libertad de los intérpretes ha sabido construir monumentos de sabiduría jurídica: es precisamente esta corriente de pensamiento la que ha dado vida, de forma implícita, pero también explícita, a una auténtica "sociología del derecho".

[...] Eugen Ehrlich, autor de la primera gran obra dedicada explícitamente a la disciplina (Fundamentos de la Sociología del Derecho), escribe desde un jurista y quiere construir, frente a la ciencia jurídica de su tiempo, conceptualista y formalista, una ciencia jurídica alternativa en cuanto sociológica. No diferente resulta, en el fondo, la intención de Santi Romano, ilustre representante de la cultura jurídica italiana, que se opone a la corriente dominante del formalismo de su tiempo y teoriza, en L'ordinamento giuridico, la identificación entre ordenamiento jurídico y organización social, por él denominada institución (Ferrari, 2000, pp. 66-67).

Estos postulados tienen la dificultad de su aceptación por parte de abogados y profesores en las facultades de derecho latinoamericanas de que existe una sociología y antropología jurídica que sustenta sus estudios en prácticas jurídicas paralelas u opuestas al Estado-nación moderno.

\section{CONFLICTO Y PLURALISMO JURÍDICO}

La negación y el desconocimiento del conflicto social por una parte de profesionales de las ciencias sociales como abogados, antropólogos y ciertos sociólogos, contradictoriamente es esencial para las especialidades de la ciencia jurídica, como la 
antropología jurídica que se ha caracterizado en los tiempos recientes por analizar las relaciones conflictivas que surgen en los distintos contextos sociales y culturales, es así como el antropólogo jurídico Esteban Krotz relaciona los conflictos con las reglas en diversos contextos sociales: Este sistema de reglas se ocupa ante todo de conflictos. Las reglas de la ley definen aquellos conflictos que en un momento dado considera altamente relevantes o esenciales la sociedad respectiva. Es decir, de entre la multitud prácticamente infinita de conflictos que se producen permanentemente en cualquier tejido de relaciones sociales, el sistema de reglas legales selecciona aquellos conflictos -o sea: declara su existencia y los jerarquiza- que la sociedad o el grupo social en cuestión considera de algún modo, y por alguna razón fundamental para su identidad, permanencia y reproducción. Mediante el establecimiento de tales reglas, la sociedad trata de evitar estos conflictos, de solucionar los problemas que transgredan las normas legales y en caso de judicialización busca solucionarlos vía administración de justicia y con ello evitar posibles conflictos sociales a futuro (Krotz, 2002, pp. 32-33).

Por su parte, el derecho comparado, propio de la formación jurídica, intenta relacionar los fenómenos de regulación y control entre distintas situaciones de confrontación y transgresión entre grupos específicos, el antropólogo Clifford Geertz reflexiona sobre el derecho comparado y el conflicto: Me parece que los principales enfoques del derecho comparado -ya conciban su tarea como un contraste entre distintas estructuras normativas, o bien como un contraste entre procesos diferentes de resolución de contenciosos en sociedades diferentes- pasan en ambos casos por alto en un aspecto fundamental: el primero mediante una concepción superautónoma del derecho como un sistema legal separado e independiente, que lucha por defender su integridad analítica frente a los descuidos conceptuales y morales de la vida cotidiana; el segundo mediante una concepción superpolítica de éste como una colección indiferenciada, ordenada pragmáticamente, de mecanismos sociales para promover intereses y controlar conflictos por el poder (Geertz, 1994, p. 241).

Por su parte, la sociología jurídica se ha caracterizado por el estudio de los conflictos y en diferentes ámbitos de la vida social moderna y contemporánea, estas especialidades como se puede palpar tienen su encuentro en los conflictos sociales que suceden de forma constante en los diversos grupos humanos y que originan mayor claridad $y$ consistencia teórica y práctica al pluralismo jurídico. La propuesta de pluralismo jurídico se destaca por relacionar los conflictos sociales en toda su dimensión con el derecho desde la perspectiva de la sociología y la antropología jurídica: Estos casos de pluralismo jurídico, con vigencia sociológica reconocida o no por el derecho dominante, constituyen situaciones socialmente consolidadas y de larga duración, en donde se reflejan los conflictos sociales que acumulan y condensan diferencias socio-económicas, políticas y culturales, particularmente complejas y evidentes (Boaventura, 1991, p. 71).

La relación entre conflicto y pluralismo jurídico se remonta a los estudios sobre los procesos de colonización que la antropología y la sociología jurídica tendrán como debate central: el contexto sociológico básico en que se dio el interés por este problema fue, como en muchos otros asuntos, el colonialismo; es decir, la coexistencia en un mismo espacio, arbitrariamente unificado como colonia, del derecho del Estado colonizador y de los derechos tradicionales. Esta coexistencia, fuente constante de conflictos y de acomodaciones precarias, tuvo en algunos casos cobertura jurídico-constitucional (por ejemplo en la indirect rule del colonialismo inglés), mientras que en otros fue un fenómeno sociológico y político de rebeldía de las concepciones jurídico-políticas oficiales del Estado colonizador (lo que, en buena parte, sucedió con el colonialismo portugués) “[...] Fue 
la investigación de estos asuntos lo que ocupó en buena parte a la antropología y la sociología del derecho" (Boaventura, 1991, p. 70).

Esta situación de pluralismo jurídico se mantendrá con ciertas variables en los tiempos recientes con la categoría del neocolonialismo, al plantearse la existencia del derecho colonial de la nación hegemónica y el reconocimiento de los derechos tradicionales y locales en un mismo espacio, realizando ruptura con la concepción positivista del derecho moderno que tiene como centro de producción jurídica al Estado-nación, en el contexto de colonización se reconocen como central al derecho transnacional de los Estados expansionistas y los derechos locales de las culturas tradicionales que en ciertas circunstancias se consolidan como resistencia, en otras como complemento del derecho extranjero y en ciertas dinámicas son absorbidos por el derecho visitante.

Las diferentes situaciones que se concibieron desde el proceso de colonización en el aspecto jurídico son reseñadas por las investigadoras María Teresa Sierra y Victoria Chenaut: el colonialismo se caracteriza por la imposición de un régimen de dominación sobre la sociedad colonizada lo que viene a trastocar la estructura social en su conjunto. Tanto el derecho como la religión fueron bastiones de la empresa colonial y referentes centrales para su justificación ideológica y política:

[...] Es decir, a través del derecho se pretendía civilizar a los dominados salvajes o nativos en contra de sus costumbres. Esta misión civilizatoria de la ley puede generalizarse a toda empresa colonial, si bien en cada país tuvo sus propias características [...] En el caso de las colonias bajo dominación inglesa a través del llamado gobierno indirecto (Indirect rule), se incorporaron los ordenamientos tradicionales enmarcados dentro de ciertas jurisdicciones, para fines de la dominación. Los representantes coloniales sirvieron de engrane entre el poder colonial y el poder nativo; sin embargo el derecho cumplió un doble papel: así como contribuyó a instaurar estructuras de dominación, quitando la tierra a los campesinos o nativos, convirtiéndoles en fuerza de trabajo y disciplinándolos, más adelante proveyó también la posibilidad para que estos grupos se rebelaran en contra de los colonizadores, recurriendo a sus mismos instrumentos ideológicos. El derecho se convirtió así en una arena de disputa entre los distintos grupos de interés colonial [...]. En este sentido, como apunta Merry (1991), el derecho promueve transformaciones culturales en los colonizados, al mismo tiempo que establece los límites a las mismas y ofrece oportunidades para resistir (Sierra \& Chenaut, 2002, pp. 141-142).

A la mayoría de los profesores universitarios y sus estudiantes provenientes de los programa de derecho no les interesaba dicha temática de las relaciones sociales y el derecho desde la perspectiva de especialidades como la sociología jurídica, más aún propuestas como el pluralismo jurídico se encontraban por fuera de los debates de las disciplinas jurídicas, afectando las transformaciones que se asisten en cualquier empresa científica, así lo describe el profesor Germán Silva:

Saberes con una pertinencia directa a los derechos sustancial y procesal penal como la sociología, la psicología, la economía, la antropología, la historia, la ciencia política y la filosofía se encuentran desterrados [...] .Aunque las obras de derecho penal general son más que propicias para la intervención de la filosofía, y en parte de la sociología, pocas veces participan como competencia [...]. Incluso algunos autores que han incursionado simultáneamente en el derecho penal especial y la criminología o la política penal en el primero de los campos desechan fuentes interdisciplinarias y las interpretaciones críticas fundadas en la lectura de la realidad social, ajustándose estrictamente al método de la dogmática jurídica [...]. La integración en el análisis jurídico del bagaje y las líneas teóricas de la filosofía, la historia y las ciencias sociales y humanas resulta útil como fuente para la construcción de la teoría del derecho. De por sí, no hay teoría ju- 
rídica de envergadura que no encuentre sus pilares en la filosofía o la sociología. De otra parte, las mismas materias son instrumentos adecuados para coadyuvar al análisis de los problemas sociales o de hechos que incumben al derecho, de tal manera que la complejidad de los fenómenos no sea desconocida. Sin embargo, las dos posibilidades señaladas son desperdiciadas (Silva, 2001, pp. 120-121).

Pero los debates académicos que pareciesen exclusivos de ciertos especialistas de la sociología y la antropología jurídica en el contexto latinoamericano continuaban, para Boaventura, el conflicto y el pluralismo jurídico se encontraban no sólo en el proceso de colonización, sino era parte de las sociedades capitalistas modernas y complejas debido a las tensiones que surgían entre las clases sociales y los grupos étnicos que conformaban los Estado-nación, los conflictos en las sociedades capitalistas contemporáneas para el profesor Boaventura se encuentran relacionadas con las prácticas y expresiones del pluralismo jurídico:

\begin{abstract}
La conveniencia de ampliar el concepto de pluralismo jurídico, de tal manera que cubra situaciones susceptibles de ocurrir en sociedades cuya homogeneidad es siempre precaria porque se define en términos clasistas; esto es en las sociedades capitalistas. En estas sociedades, la homogeneidad es, en cada momento histórico, el producto concreto de las luchas de clases, y por eso encierra contradicciones (interclasistas, pero también intraclasistas) que nunca son puramente económicas y, por el contrario, constituyen un tejido de dimensiones sociales, políticas y culturales entrelazadas [...]. Una de esas expresiones es precisamente la situación del pluralismo jurídico y tiene lugar siempre que las contradicciones se condensan en la creación de espacios sociales, más o menos segregados, en el seno de los cuales se generan litigios o disputas (Boaventura, 1991, pp. 71-72).
\end{abstract}

Estas situaciones de conflicto interclasista han sido descritas en sociedades de mayor complejidad como los Estados Unidos por parte de los sociólogos jurídicos norteamericanos, especialidad que como se ha dicho anteriormente tiene un desarrollo académico reconocido y de tradición, el movimiento derecho y sociedad de la sociología jurídica norteamericana ha venido realizando estudios sobre los conflictos y las clases sociales:

\begin{abstract}
La dimensión antropológica de los conflictos también fue objeto de importantes estudios. En segundo lugar, el tema de la pirámide de la litigiosidad recibió especial atención. Estos estudios ponían de presente la idea de que la justicia sólo procesa y resuelve una mínima parte de los conflictos sociales y por tanto era necesario estudiar la manera como otros mecanismos no oficiales de resolución de conflictos operan en la sociedad [...]. El marcado interés por el derecho en todas sus manifestaciones $y$, de manera especial, por el litigio, es una de las particularidades de la sociedad estadounidense. La sociología jurídica no ha sido ajena a este fenómeno. William Hurst (1950) estudió el crecimiento y la especialización de la profesión legal en relación con los clientes y el mercado del litigio. A partir de esta investigación, considerada como un clásico en la sociología del derecho, otros estudiaron la disponibilidad de abogados en estratos bajos de la población $y$, en general, la relación entre el comportamiento de los abogados y las diferentes clases sociales (García, 2003, p.7).
\end{abstract}

\section{Transformaciones del Estado y pluralismo jurídico}

El pluralismo jurídico se convierte en la categoría de la ciencia jurídica que vincula el conflicto social en toda su amplitud en relación con el derecho, comprendiendo la complejidad de los diversos derechos que se encuentran tanto en las sociedades capitalistas contemporáneas y que interactúan en un determinado contexto, como en los derechos y prácticas jurídicas de las culturas tradicionales, o la relación entre los derechos de sociedades capitalistas y tradicionales en un solo espacio, sin importar los conflictos que surjan al interior de las diferentes sociedades y culturas. Clifford Geertz 
reflexiona sobre el derecho y su a relación con la cultura, y el pluralismo legal:

La concepción del estudio comparado del derecho como ejercicio de traducción intercultural; la idea de que el pensamiento legal estructura las realidades sociales en lugar de reflejarlas simplemente; el acento sobre la tenacidad histórica de las sensibilidades legales; el rechazo de una relación sobre la fuerza práctica del derecho basada en el consenso social a favor de otra que lo esté en la búsqueda de su sentido; la convicción de que el pluralismo legal no es una aberración pasajera, sino una característica central del paisaje moderno; $y$ el argumento de que la autocompresión y la compresión del otro se hallan tan internamente conectadas en el derecho como lo están en los restantes ámbitos de la cultura -todas estas apreciaciones son producto de una cierta forma de pensar, por lo demás bastante fascinada por la diversidad de las cosas (Geertz, 1994, pp. 259-260).

Este concepto o categoría de la ciencia jurídica se convierte en la posibilidad que tienen los profesionales del derecho, en particular y los profesionales de la ciencia jurídica y social, en general, de introducirse en los estudios sobre los diversos conflictos sociales (incluyendo el conflicto armado) que se devienen en el contexto colombiano. Los avances del pluralismo jurídico al reconocer las prácticas jurídicas diferentes al derecho estatal al interior de la teoría del derecho y de las especialidades de la ciencia jurídica como la filosofía, antropología y sociología del derecho que plantearon el debate conceptual en sus inicios, son recogidos contradictoriamente por cierto sector considerado como de sus más acérrimos detractores, los defensores del positivismo jurídico tradicional y de la vigencia de un solo derecho, el estatal, para impulsar las transformaciones del Estado capitalista y adecuarse al devenir histórico que en cierta manera se impulsa desde la misma lógica, claro está con sus respectivas contradicciones que en algunos momentos son reguladas y en otros, la estabilidad del sistema se encuentra cuestionada, impidiendo su avance y reproducción.

El investigador Andrea Hoekema reseña cómo el Estado moderno en un tiempo reducido, pasa de la aplicación del derecho estatal al reconocimiento del pluralismo jurídico:

\begin{abstract}
Antes, en los años cincuenta y sesenta, las políticas de desarrollo de muchos países se orientaban a un concepto de modernidad que implicaba la abolición y represión total de otros sistemas de derecho y autoridad diferentes de los estatales. Se atacaba por todos los medios una visceral lealtad a comunidades y aun liderazgo no estatal que pudiera oponerse a las leyes y directivas nacionales [...]. Muchos países reconocen ahora que dentro de la reforma del Estado se contemple seriamente la necesidad de transferir recursos y atribuciones a la sociedad: a comarcas, distritos, municipios y comunidades; este aspecto haría parte de un cambio radical de las estructuras estatales y legales en casi todo el mundo, puesto que abre oportunidades para conquistar formas políticas y legales que van más allá de una mera descentralización del Estado y de su filosofía de agilizar los procesos administrativos; abre además oportunidades para avanzar hacia formas políticolegales que encarnen una plurietnicidad, una pluralidad de derecho y una autoridad genuina (Hoekema, 2002, pp. 63-64).
\end{abstract}

Los Estados considerados como "avanzados" en el capitalismo, en forma constante y permanente sufren transformaciones para limitar las contradicciones que se tejen desde su interior y expandir la lógica del mercado en que se sustenta, estas transformaciones afectan el soporte esencial para su reproducción desde sus inicios, la ciencia y el derecho (Boaventura, 1998, p. 124) estos países avanzados son por lo general quienes lideran los cambios que se consideran pertinentes para consolidar su estructura económica y la superestructura política, ideológica y cultural, es así como la administración de justicia que se desprende del 
Estado-nación de la modernidad debe realizar los correctivos pertinentes para estar a la par con las exigencias del momento, lo que se cuestionaba e incluso se perseguía por ser contrario a la ley y el orden se vincula como parte de lo jurídico, como son las prácticas informales de la justicia como por ejemplo los mecanismos de conciliación de conflictos (Silva, 2001, p. 168).

Las transformaciones del Estado moderno necesariamente impactan el sistema judicial impulsando reformas a su interior con efectos externos:

Las reformas propuestas son principalmente de dos tipos y además, en apariencia, contradictorios: el primer tipo propone transformaciones profundas en la concepción el sistema judicial, instrumentándolo con múltiples y sofisticadas innovaciones técnicas que van de la automatización de los ficheros y archivos [...] al uso generalizado de la tecnología del video, las técnicas de planeamiento de largo plazo, y la elaboración de módulos y de cadenas de decisión que tornen posible la rutinización. Pero a más de estas innovaciones técnicas de por sí ambiciosas, estas reformas hacen indispensable la formación de una serie de profesionales nuevos y nuevas formas de centralización y unificación de los procesos judiciales. Por todo esto, este primer tipo de reformas, parece apuntar hacia lo que se puede designar como Administración tecnocrática de la justicia. El segundo tipo de reformas, muy distinto del anterior, se caracteriza por la elaboración de alternativas al modelo centralizado formal y profesionalizado que ha dominado la administración de justicia sobre todo en los últimos 200 años. Estas alternativas diversa y genéricamente conocidas como informatización de la justicia, deslegalización, justicia comunitaria, resolución de conflictos y procesamientos de litigios- consisten en general en la creación de procesos, instancias e instituciones relativamente descentralizados, informales y despersonalizados que sustituyan o complementen en áreas determinadas la administración de justicia y la tornen en general más rápida, más barata y más accesibles (Boaventura, 1991, p. 124).
La introducción de las prácticas de resolución de conflictos en el contexto colombiano ha logrado ciertos avances y desarrollos en el campo jurídico, las posibilidades de acrecentar o sostener el dominio de los operadores jurídicos sobre el manejo de muchos asuntos enfrenta a los movimientos de resolución alternativa de conflictos y desjudicialización de ciertas causas, quienes fundamentan, en parte, sus discursos de reforma legislativa en una crítica a la cultura de la litigiosidad que contamina a los abogados. Aquí es necesario preguntarse, sin embargo, si todos los asuntos que son turnados a aquellas franjas donde es factible un tratamiento no institucionalizado o paralelo del conflicto son de interés para los operadores jurídicos. Así mismo, respecto del caso colombiano, será necesario indagar hasta qué punto los operadores del derecho han ocupado también los espacios previstos para los tratamientos llamados alternativos.

\begin{abstract}
Es probable que el primer interrogante deba absolverse de modo negativo y el segundo de manera más o menos positiva. De hecho de la segunda cuestión debe considerarse que el desarrollo de los medios denominados alternativos han favorecido el surgimiento de abogados especializados en los más importantes procedimientos previstos al efecto, junto a agencias burocráticas encargadas de gestionarlos o promoverlos (Silva, 2001, p. 168).
\end{abstract}

\section{CONCLUSIÓN}

Las especialidades de la sociología y la antropología jurídica paulatinamente han logrado en las últimas décadas ampliar su horizonte en las facultades de derecho latinoamericanas particularmente por factores externos como la tradición y fortaleza que estas especialidades han adquirido en los contextos académicos centrales y de fuerte tradición jurídica como el anglosajón y el continental europeo, a lo que se suma la formación jurídica que adquieren los investigadores locales al formarse en estudios avanzados en universida- 
des de prestigio internacional y los intercambios académicos de forma periódica que se realizan en lo regional y lo global, entre otros, factores que ya inciden en los planes de estudio y en los centros de investigación que se crean y consolidan de forma permanente en universidades de incidencia nacional y local, estos progresos son interesantes, mas se encuentran en su fase incipiente y deben proyectarse para configurar movimientos académicos que desde las especialidades jurídicas y lo interdisciplinario puedan convertir a la ciencia jurídica en la responsable de pretender resolver los complejos conflictos sociojurídicos que asistimos en los inicios de este siglo.

Entre los estudios que se deben adelantar por estas especialidades analíticamente son las transformaciones estatales que incorporan al rechazado pluralismo jurídico en sus estrategias innovadoras de expansión, las prácticas jurídicas locales como la justicia comunitaria o la justicia indígena que se reconocieron por los críticos del derecho como alternativas al derecho dominante por ciertas tendencias o de resistencias e insurgentes por otros enfoques y rechazadas de forma radical por parte de los defensores del positivismo; la legalidad, por consiguiente, del único derecho posible, el derecho estatal, de forma irónica, son vinculadas por medio de su reconocimiento a las prácticas de regulación que se originan desde el Estado central con el objetivo de expandir su presencia desde un imaginario más conciliador, distinto al represivo que se caracterizó en varias décadas de dominación, situación que se relaciona con la expansión simbólica y real de las sociedades modernas y capitalistas, esta vinculación se hace desde las reformas constitucionales que se han realizado recientemente en las naciones latinoamericanas, que para el caso colombiano se contextualiza por medio de las jurisdicciones especiales de paz e indígena.

\section{REFERENCIAS}

Boaventura, S. (1991). Estado, derecho y luchas sociales. Bogotá: ILSA.

Boaventura, S. (1998). La globalización del derecho. Bogotá: ILSA.

Bobbio, N. (1999). Teoría general del derecho. Bogotá: Temis.

Carduño, G. \& Silva, G. (Comp.) (1998). Antología. Teoría sociológica clásica. Max Weber. México: UNAM.

Ferrari, V. (2000). Acción jurídica y sistema normativo. Introducción a la sociología del derecho. Madrid: Dykinson.

García, M. (2001). Sociología jurídica. Teoría y sociología del derecho en Estados Unidos. Bogotá: Universidad Nacional de Colombia.

García, M. (2003). Estudio preliminar. En: Sociología jurídica. Teoría y sociología del derecho en Estados Unidos. Bogotá: Universidad Nacional de Colombia.

Geertz, C. (1994). Conocimiento local. Ensayos sobre la interpretación de las culturas. Barcelona: Paidós.

Hoekema, A. (2002). Hacia un pluralismo jurídico formal de tipo igualitario. En: Revista El Otro Derecho. 26-27. Bogotá: ILSA.

Krotz, E. (2002). Sociedades, conflictos, cultura y derecho desde una perspectiva antropológica. En: Antropología jurídica: perspectivas socioculturales en el estudio del derecho. México: Anthropos.

Moncayo, H. (1991). Presentación. En: Estado, derecho y luchas sociales. Bogotá: ILSA. 
Ost, F. \& Kerchove, M. (2001). Elementos para una teoría crítica del derecho. Bogotá: Universidad Nacional de Colombia.

Sierra, M. \& Chenaut, V. (2002). Los debates recientes y actuales en la antropología jurídica: Las corrientes anglosajonas. En: Antropología jurídica: Perspectivas socioculturales en el estudio del derecho. México: Anthropos.

Silva, G. (s.f.). El mundo real de los abogados y de la justicia. Tomo I. Bogotá: Universidad Externado de Colombia.
Twining, W. (2003). Derecho y globalización. Bogotá: Siglo del Hombre Editories.

Varela, R. (2002). Naturaleza/cultura, poder/política, autoridad/legalidad/legitimidad. En: Krotz, E. (2002). Antropología jurídica: Perspectivas socioculturales en el estudio del derecho. México: Anthropos.

Wolkmer, A. (2003). Introducción al pensamiento jurídico crítico. Bogotá: ILSA. 